\title{
Development of Analytical Procedures for Lead Determination in Incense by Graphite Furnace AAS
}

\author{
Jessica Coco ${ }^{a}$, Marcos A. Bechlina, Ariane I. Barros ${ }^{a}$, Edilene C. Ferreira ${ }^{a}$, \\ Marcia A.M.S. Veiga ${ }^{b}$, and José A. Gomes Neto ${ }^{\circ},{ }^{a}$ \\ a São Paulo State University, Institute of Chemistry, 14800-060, \\ Araraquara, SP, Brazil \\ b Departamento de Química, Faculdade de Filosofia, Ciências e Letras de Ribeirão Preto, \\ University of Sao Paulo (FFCLRP/USP), Ribeirao Preto, SP, Brazil
}

\section{INTRODUCTION}

Incense is used worldwide for a variety of purposes, including religious ceremonies, to repel insects, for aromatherapy, meditation, room scents, etc. (1). The U.S. market for incense in 1999 represented \$16.8 million (2). Direct-burning of incense (e.g., incense sticks) releases not only fragrant smoke, but also gaseous pollutants (e.g., carbon monoxide, nitrogen oxides, volatile toxic metals) (3). Raw materials used in the manufacturing of incense can contain hazardous metals such as arsenic, cadmium, lead, mercury, and their compounds (4). The toxic effects of these metals on the environment (microorganisms, plants, animals) and to human health have been studied and the literature presents reviews on the matter (5). However, regulatory requirements for incense with emphasis on hazardous metals are not defined. Since the consumption of incense and related products has increased, the development of simple, fast, and rugged analytical methods for incense analysis is relevant for routine quality assessment.

Spectrometric techniques are suitable for the elemental analysis of incense and include inductively coupled plasma optical emission spectrometry (ICP OES), inductively coupled plasma mass spectrometry (ICP-MS), atomic absorption spectrometry (AAS), where graphite furnace (GF) AAS is best known for its practicality, agility, high sensitivity and selectivity, low

\section{ABSTRACT}

The use of incense has increased over the past years; however, few studies have been carried out concerning the quantification of toxic elements. This article describes the development of analytical methods for $\mathrm{Pb}$ determination in the rod and coating of incense sticks by solid sampling high-resolution continuum source graphite furnace atomic absorption spectrometry (SS HR-CS GFAAS). For comparative purposes, samples were also analyzed by line source graphite furnace atomic absorption spectrometry (LS GFAAS) after acid microwave-assisted digestion. The concentration of lead varied

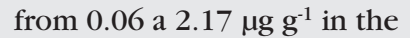
rods and 1.06 to $6.60 \mu \mathrm{g} \mathrm{g}^{-1}$ for the coating. A paired $t$-test at a 95\% confidence level showed that the SS HR-CS GFAAS results were in agreement with those obtained by LS GFAAS. The precision of measurements obtained by SS HR-CS GFAAS varied from 0.5 to $16 \%$ and 1.9 to $15 \%$ for rod and coating, respectively. Also, emission of lead generated when the incense stick samples were burning was evaluated by ash analysis and the mass balance applied for total lead in the whole samples and the remaining lead in the ashes. These findings showed that 25 to $80 \%$ of the total lead content in incense may be released to the air. These large variations may be related to the type of raw materials (chemical composition) employed in incense production. cost, and the ability for use in solid sampling (6).

In this context, line-source GFAAS (LS GFAAS) and high-resolution continuum source GFAAS (HRCS GFAAS) were selected as the analytical techniques to investigate new methods for $\mathrm{Pb}$ determination in incense. For LS GFAAS, a sample preparation procedure based on microwave-assisted digestion in closed vessels was developed. Alternatively, another method was developed based on direct solid sample analysis by HR-CS GFAAS. This technique has proven to be feasible for solid sampling such as biological tissues $(7,8)$, environmental samples $(9,10)$, coal $(11,12)$, hair (13), medicinal plants $(14,15)$, rice grains (16), glass (17), and makeup (18), but studies on incense are scarce.

The present study reports the development of a simple, fast, and rugged method for $\mathrm{Pb}$ determination in incense by HR-CS GFAAS using solid sampling. The method was applied to the $\mathrm{Pb}$ determination in different incense sticks and accuracy was assessed by comparing the results with those obtained by LS GFAAS after sample digestion.

\section{EXPERIMENTAL}

\section{Instrumentation}

A high-resolution continuum source atomic absorption spectrometer AnalytikJena ContrAA 700 (Jena, Germany), equipped with a short-arc Xenon lamp operated in "hot-spot" mode as continuum radiation source and a high-resolution double monochromator with a charge-coupled device (CCD) detector, was used for absorbance 
measurements. Lead was monitored at $283.306 \mathrm{~nm}$ with peak volume selected absorbance (integrated peak absorbance) equivalent to 3 pixels $(C P \pm 1$; $C P$ : central pixel corresponding to the center of the line). Solid sampling tubes (without a dosing hole), coated with transversely heated pyrolytic graphite, were used. The samples were weighed directly onto solid sampling platforms using a Sartorius WZ2PW microbalance (Göttingen, Germany) with an accuracy of $0.001 \mathrm{mg}$. The platforms were inserted into the graphite furnace using an SSA 600 solids autosampler. High purity argon (99.999\%, White Martins, Sertãozinho, Brazil) was used as the purge and protection gas. The heating program of the graphite furnace for $\mathrm{Pb}$ measurement by HR-CS GFAAS is presented in Table I.

A PerkinElmer ${ }^{\circledR}$ AAnalyst $^{\mathrm{TM}} 800$ line-source atomic absorption spectrometer (Shelton, CT, USA) with a longitudinal Zeeman-effect background correction system, equipped with a transversely heated graphite tube atomizer (THGA) with integrated platforms and an AS-72 autosampler, was used for the measurements by LS GFAAS. An electrodeless discharge lamp was employed for $\mathrm{Pb}$ determination at $283.3 \mathrm{~nm}$ operated at 450 $\mathrm{mA}$. The atomic absorption signals were measured in triplicate. Highpurity argon (99.999\%, White Martins) was used as the purge gas. The heating program of the graphite furnace for $\mathrm{Pb}$ measurement by LS GFAAS is presented in Table II.

A cryogenic mill SPEX Freezer Mill 6800, equipped with polycarbonate tubes, was used for grinding the samples. An analytical balance with a precision of $0.0001 \mathrm{~g}$ was used for mass measurements. Microwave-assisted acid digestion was carried out employing a Multiwave ${ }^{\circledR}$ microwave oven (Anton Paar GmbH, Graz, Austria) equipped with 25-mL quartz vessels.

\section{Reagents and Analytical Solutions}

High purity water was obtained using a Millipore Rios $5^{\circledR}$ reverse osmosis and a Millipore Milli-Q ${ }^{\circledR}$ Academic $^{\circledR}$ deionizer system (resistivity $18.2 \mathrm{M} \Omega \mathrm{cm}$, Millipore Corporation, Bedford, MA, USA) and were used throughput the work. Nitric acid (Suprapur ${ }^{\circledR}$, Merck, Darmstadt, Germany) and hydrogen peroxide (30\% m/m, Merck, Germany) were used for sample digestion.

A $1000-\mathrm{mg} \mathrm{L}^{-1} \mathrm{~Pb}$ standard stock solution (Specsol, Brazil) was properly diluted daily to prepare the analytical solutions ranging from 100-1000 pg Pb (aliquots of 1.0-10 $\mu \mathrm{L}$ of $100 \mu \mathrm{g} \mathrm{L^{-1 }} \mathrm{Pb}$ ) and 5.0-50 $\mu \mathrm{g}$ $\mathrm{L}^{-1} \mathrm{~Pb}$ for HR-CS GFAAS and LS GFAAS, respectively. The analytical solutions were acidified to $1.0 \%$ (v/v) $\mathrm{HNO}_{3}$. A Pd/Mg mixture was employed as the conventional modifier (Fluka, Switzerland). A solution containing $0.1 \%(\mathrm{~m} / \mathrm{v}) \mathrm{Pd}\left(\mathrm{NO}_{3}\right)_{2}+$ $0.05 \%(\mathrm{~m} / \mathrm{v}) \mathrm{Mg}\left(\mathrm{NO}_{3}\right)_{2}$ was prepared by proper dilution of the stock solutions in $0.05 \%(\mathrm{v} / \mathrm{v})$ of Triton ${ }^{\circledR}$ X-100 (Mallinckrodt, Paris, KY, USA).

\section{Sample Preparation}

Nine incense samples from different countries (China, India, and Brazil) were purchased at a local market in Araraquara City, São Paulo, Brazil. The average mass of whole incense sticks, coating, and rods were determined by weighing eight samples from the same package. The samples were fractioned into two parts (coating and rod) by removing the surface layer by means of a plastic spatula, and the fractions were cryogenically ground to small particle sizes $(<100 \mu \mathrm{m})$.

For comparison, all samples were prepared in triplicate by microwave-assisted acid digestion. A mass of approximately $0.2 \mathrm{~g}$ was accurately weighed and transferred into the microwave flasks, followed by addition of $3.0 \mathrm{~mL}$ concentrated
TABLE I

Optimized Heating Program for Lead Determination in Incense by SS HR-CS GFAAS

\begin{tabular}{lrrrc}
\hline Steps & $\begin{array}{c}\text { Temp. } \\
\left({ }^{\circ} \mathrm{C}\right)\end{array}$ & $\begin{array}{c}\text { Ramp } \\
\left({ }^{\circ} \mathrm{C} \mathrm{s}^{-1}\right)\end{array}$ & $\begin{array}{c}\text { Hold } \\
\text { Time } \\
(\mathrm{s})\end{array}$ & $\begin{array}{c}\text { Argon } \\
\text { Flow Rate } \\
\left(\mathrm{L} \mathrm{min}^{-1}\right)\end{array}$ \\
\hline Drying 1 & 110 & 10 & 10 & 2.0 \\
Drying 2 & 130 & 5 & 10 & 2.0 \\
Pyrolysis & 1200 & 100 & 30 & 2.0 \\
Auto-zero* & 1200 & 0 & 5 & 0 \\
Atomization & 2200 & 3000 & 5 & 0 \\
Cleaning & 2750 & 500 & 5 & 2.0 \\
\hline
\end{tabular}

*Step to ensure that the atomization starts without the presence of argon.
TABLE II

Heating Program for $\mathbf{P b}$ Determination in Incense by LS GFAAS as Comparative Technique

\begin{tabular}{lcccc}
\hline Steps & $\begin{array}{c}\text { Temp. } \\
\left({ }^{\circ} \mathrm{C}\right)\end{array}$ & $\begin{array}{c}\text { Ramp } \\
\left({ }^{\circ} \mathrm{C} \mathrm{s}^{-1}\right)\end{array}$ & $\begin{array}{c}\text { Hold } \\
\text { Time } \\
(\mathrm{s})\end{array}$ & $\begin{array}{c}\text { Argon } \\
\text { Flow Rate } \\
\left(\mathrm{L} \mathrm{min}^{-1}\right)\end{array}$ \\
\hline Drying 1 & 110 & 1 & 10 & 250 \\
Drying 2 & 130 & 10 & 10 & 250 \\
Pyrolysis & 1200 & 10 & 30 & 250 \\
Atomization & 2000 & 0 & 5 & 0 \\
Cleaning & 2500 & 1 & 5 & 250 \\
\hline
\end{tabular}


nitric acid, $1.0 \mathrm{~mL}$ hydrogen peroxide $(30 \% \mathrm{~m} / \mathrm{m})$, and $2.0 \mathrm{~mL}$ deionized water. Then, the following optimized program of the microwave oven was run: (a) 15 minutes from 0 to $700 \mathrm{~W}$; (b) 15 minutes from 700 to $1000 \mathrm{~W}$; (c) $15 \mathrm{~min}$ utes at $1000 \mathrm{~W}$, and (d) 30 minutes at $0 \mathrm{~W}$ (ventilation). After cooling, the clear digests were transferred to $25-\mathrm{mL}$ volumetric flasks and made up to volume with deionized water.

\section{Analytical Procedure}

The thermal behavior of $\mathrm{Pb}$ was evaluated by means of pyrolysis at $400-1600{ }^{\circ} \mathrm{C}$ and atomization at $1600-2400{ }^{\circ} \mathrm{C}$ with the temperature curves built up in aqueous medium (250 pg $\mathrm{Pb}$ ) and solid media (0.45-0.55 mg of rod and coating) in the presence of $5 \mu \mathrm{g}$ $\mathrm{Pd}\left(\mathrm{NO}_{3}\right)_{2}+2.5 \mu \mathrm{gg}\left(\mathrm{NO}_{3}\right)_{2}$ as the conventional modifier. All absorbance measurements were carried out in triplicate.

The matrix effects were evaluated by means of calibration curves built up in the aqueous and solid media. Different aliquots (1.0 $10.0 \mu \mathrm{L}$ ) of a $100-\mu \mathrm{g} \mathrm{L}^{-1}$ standard solution were delivered to the solid platform in order to produce a calibration in the $100-1000 \mathrm{pg} \mathrm{Pb}$ mass range. Calibration with solid standards was performed by placing different masses (from $0.05 \mathrm{mg}$ to $1.05 \mathrm{mg}$ in $0.1 \mathrm{mg}$ increments) of rod and coating onto the platform. All measurements were carried out in triplicate.

The limits of detection (LOD) and quantification (LOQ) were determined according to the IUPAC recommendations: $3 \mathrm{xSD}_{\text {blank }} / \mathrm{b}$ (LOD) and $10 \times \mathrm{xD}_{\text {blank }} / \mathrm{b}$ (LOQ), where $\mathrm{SD}$ is the standard deviation for 10 blank measurements (using an empty platform) and $b$ is the angular coefficient of the calibration curve (19).

The influence of sample size on precision and accuracy was investi- gated by evaluating the minimum mass of rod and coating to be analyzed from $0.05 \mathrm{mg}$ to $1.05 \mathrm{mg}$ in $0.1 \mathrm{mg}$ increments. Each mass interval represents the average of three sample masses. The homogeneity factor $\left(\mathrm{H}_{\mathrm{e}}\right)$ was calculated according to the literature (20).

After optimization, the method was applied to the analysis of nine incense stick samples and their fractions. Sample masses around $0.5 \mathrm{mg}$ were weighed directly onto the graphite platform, followed by $5.0 \mu \mathrm{L}$ of $\mathrm{Pd}\left(\mathrm{NO}_{3}\right)_{2} / \mathrm{Mg}\left(\mathrm{NO}_{3}\right)_{2}$ conventional modifier solution. The platform was automatically introduced into the graphite furnace for analysis and the determinations were carried out in triplicate. For ashes, masses around $0.3 \mathrm{mg}$ were analyzed.

For comparing the results obtained with the proposed HR-CS GFAAS method, the samples were digested and $\mathrm{Pb}$ determined by the LS GFAAS comparative technique. For this, measurements were done in triplicate after injecting $20 \mu \mathrm{L}$ of the blank, analytical solutions, and sample digests, followed by $5.0 \mu \mathrm{L}$ of $\mathrm{Pd}\left(\mathrm{NO}_{3}\right)_{2} / \mathrm{Mg}\left(\mathrm{NO}_{3}\right)_{2}$ modifier solution, and performing the heating program as described in Table II.

\section{RESULTS AND DISCUSSION}

\section{Method Development for the Determination of Lead}

First, the experiments were carried out to evaluate the thermal behavior of $\mathrm{Pb}$ and to develop the heating program of the atomizer of the HR-CS GFAAS spectrometer. The thermal behavior of $\mathrm{Pb}$ was evaluated by means of pyrolysis and atomization temperature curves built up in aqueous medium and solid media in the presence of $5 \mu \mathrm{g}$ $\mathrm{Pd}\left(\mathrm{NO}_{3}\right)_{2}+2.5 \mu \mathrm{gg}\left(\mathrm{NO}_{3}\right)_{2}$ as chemical modifier. As is shown in Figure 1, the pyrolysis and atomization temperature curves for $\mathrm{Pb}$ are of the three different media. The coating, aqueous, and rod media stabilized $\mathrm{Pb}$ up to $1400{ }^{\circ} \mathrm{C}, 1200$ ${ }^{\circ} \mathrm{C}$, and $1000{ }^{\circ} \mathrm{C}$, respectively. The pyrolysis temperature was fixed at $1200{ }^{\circ} \mathrm{C}$ for further experiments after considering that there was no residue formation inside the graphite platform and the possibility of analyzing different fractions of incense samples. The maximum sensitivities for $\mathrm{Pb}$ in the coating, aqueous, and rod media were obtained at the atomization temperatures of $2200{ }^{\circ} \mathrm{C}, 1800{ }^{\circ} \mathrm{C}$, and $2000{ }^{\circ} \mathrm{C}$, respectively. In spite of the fact that atomization at $2200{ }^{\circ} \mathrm{C}$ did not furnish the highest integrated absorbance for $\mathrm{Pb}$ in all media, it allowed good atomic absorption peak profiles, and suitable sensitivity and precision (RSD $<3.2 \%$ ). Thus, the atomization temperature was fixed at $2200{ }^{\circ} \mathrm{C}$ for further experiments. After the establishment of the heating program, the matrix effects were evaluated by comparing the slopes of the analytical curves (Figure 2) built up in the 100-1000 pg Pb range and employing aqueous (diluted nitric acid) and solid medium of rod and coating fractions. Analysis of Figure 2 reveals good linear correlation coefficients $\left(r^{2}\right)$ between absorbance and concentration of $\mathrm{Pb}$ for each medium tested: 0.9989 (aqueous), 0.9995 (rod), and 0.9993 (coating). The slopes of the analytical curves were $0.0004 \mathrm{pg} \mathrm{s}^{-1}, 0.0005 \mathrm{pg} \mathrm{s}^{-1}$ and $0.0002 \mathrm{pg} \mathrm{s}^{-1}$ for aqueous, rod, and coating media, respectively. The characteristic mass $\left(\mathrm{m}_{0}\right)$ was obtained as the mass of analyte corresponding to an integrated absorbance of $0.0044 \mathrm{~s}$. The $\mathrm{m}_{0}$ for $\mathrm{Pb}$ (calculated as average $\mathrm{m}_{0}$ of all points over the entire calibration set) in aqueous, rod, and coating was $9.5 \mathrm{pg}, 8.2 \mathrm{pg}$, and $29 \mathrm{pg}$, respectively. These data show significant matrix effects, and expected errors close to $2.9 \%$ and $4.0 \%$ in the rod and coating analysis, respectively, if aqueous standard solutions containing $\mathrm{Pb}$ are employed as the calibration set. For 


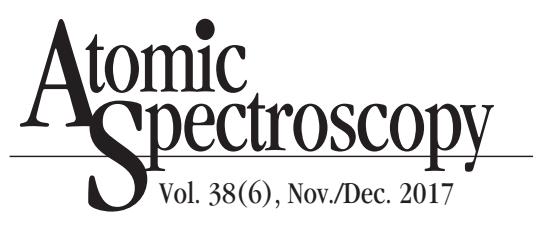

further experiments, aqueous calibration and matrix-matching calibration were selected for $\mathrm{Pb}$ determination in rods and coatings, respectively.

Studies on minimum mass and homogeneity were then conducted by analyzing different masses $(0.05$ $1.05 \mathrm{mg}$ ) of rod and coating fractions. The most accurate and precise results were obtained for sample amounts in the ranges of $0.45-0.55 \mathrm{mg}$ of rod and 0.55-0.65 $\mathrm{mg}$ of coating. The homogeneity at micro scale may be evaluated by means of the homogeneity factor $H_{e}=\mathrm{S}_{\mathrm{H}} \cdot \mathrm{m}^{1 / 2}$, in which $\mathrm{S}_{\mathrm{H}}$ is the sampling uncertainty and $\mathrm{m}$ the sample mass (20). Materials may be considered homogeneous when $H_{e}$ is lower than 10. The masses in the range of $0.45-0.55 \mathrm{mg}$ of rod and 0.55-0.65 mg of coating were considered to be homogeneous since $H_{e}$ is $<10$. Hence, masses of rod and coating around $0.5 \mathrm{mg}$ were used for all further investigations.

\section{Figures of Merit}

The limit of detection (LOD), limit of quantification (LOQ), $\mathrm{m}_{0}$, precision, linear working range, and the correlation coefficient ( $r$ ) and slope (s) of the analytical curve for the proposed method are presented in Table III. The LOD and LOQ were calculated as the concentration corresponding to 3- and 10-fold the standard deviation of the blank divided by the slope of the analytical curve. The standard deviation of the blank was calculated by repeatedly inserting an empty solid sampling platform containing only the modifier and running the temperature program (19).

\section{TABLE III}

Figures of Merit for $\mathbf{P b}$ Determination by SS HR-CS GFAAS

Using Calibration Standards in Aqueous, Rod and Coating Media

\begin{tabular}{lrrr}
\hline \multicolumn{2}{l}{ Parameters Aqueous } & Rod & Coating \\
\hline LOD (pg) & 5.0 & 5.6 & 12 \\
LOQ (pg) & 15 & 19 & 40 \\
m $_{0}$ (pg) & 9.5 & 8.2 & 29 \\
RSD (\%) & 2.9 & 4.3 & 6.1 \\
b & 0.0004 & 0.0005 & 0.0002 \\
r & 0.9989 & 0.9995 & 0.9993
\end{tabular}

LOD: limit of detection.

LOQ: limit of quantification.

$\mathrm{m}_{\mathrm{o}}$ : characteristic mass.

RSD: relative standard deviation.

b: slope.

r: correlation coefficient.

\section{Application of Analytical Proce- dure for $\mathbf{P b}$ in Real Samples}

The results obtained for $\mathrm{Pb}$ in the rod and coating fractions of nine incense samples by SS HR-CS GFAAS and a comparative technique based on LS GFAAS after acid digestion are listed in Table IV. According to the results, a paired $t$-test at the $95 \%$ confidence level showed that the SS HR-CS GFAAS procedure enabled the achievement of similar results as those obtained by LS GFAAS. The precision (RSD) of measurements obtained by SS HR-CS GFAAS varied from 0.5 to $16 \%$ and 1.9 to $15 \%$ for rod and coating, respectively. The concentration of lead varied from 0.06 to $2.17 \mu \mathrm{g} \mathrm{g}^{-1}$ in rods and 1.06 to $6.60 \mu \mathrm{g} \mathrm{g}^{-1}$ for coatings. Considering that the burning of incense sticks may result in indoor air pollution, emission of lead generated when incense stick samples were burning, was evaluated by determining lead $(n=5)$ in samples before and after burning, and applying mass balance for total lead in the whole samples and remaining lead in the ashes. These findings showed that 25 to $80 \%$ of the total lead content in incense can be released to the air. These large vari-

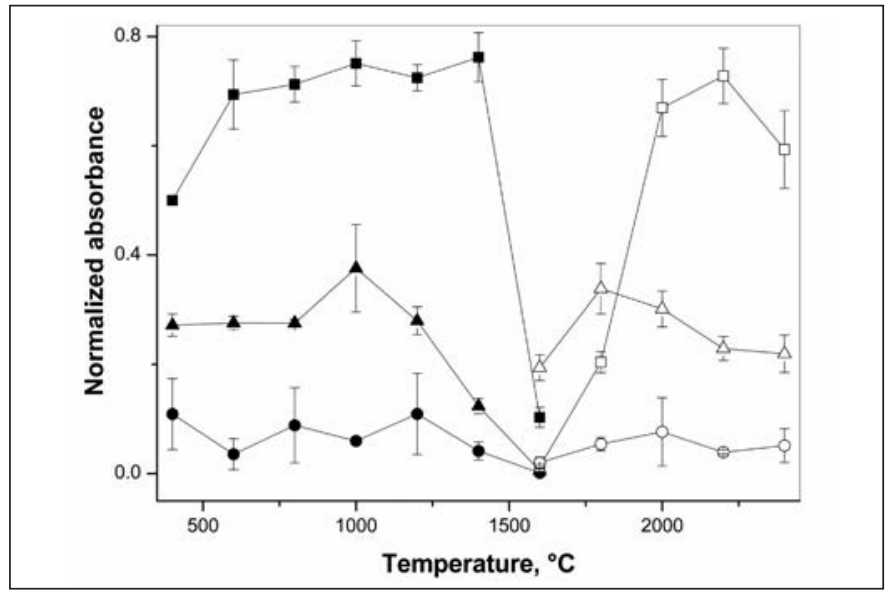

Fig. 1. Pyrolysis and atomization curves obtained for aqueous medium ( $\mathbf{\Lambda}, \triangle$ ) from $\left(2.5 \mu \mathrm{L}\right.$ of a $100 \mu \mathrm{g} \mathrm{L} \mathrm{L}^{-1} \mathrm{~Pb}$ solution) and solid medium (0.5-0.6 mg of rod $(\bullet, \bigcirc)$ and coating $(\square, \square)$, respectively).

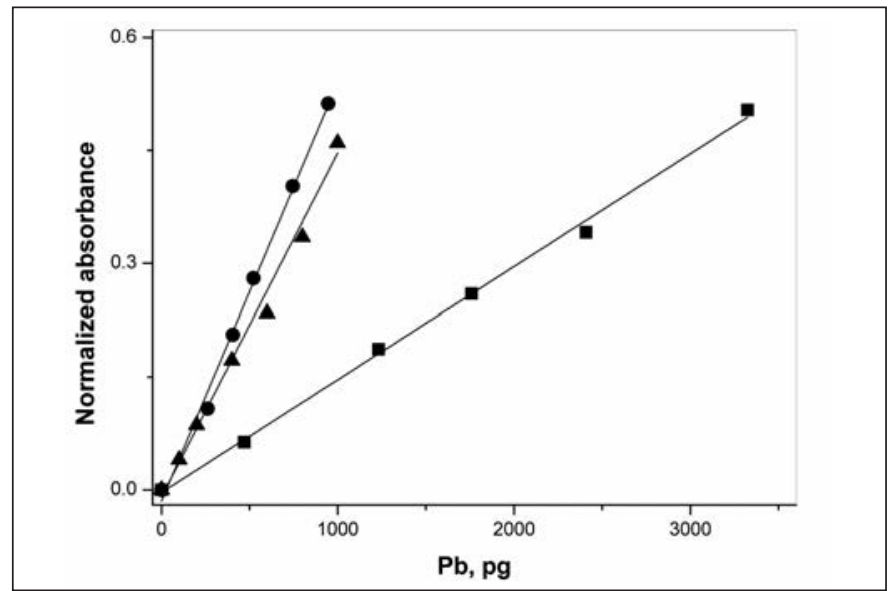

Fig. 2. Calibration curves for $\mathrm{Pb}$ in aqueous (A), $\operatorname{rod}(\mathbf{\bullet})$ and coating (ם) media obtained by SS HR-CS GFAAS. Pyrolysis temperature: $1200{ }^{\circ} \mathrm{C}$ and atomization temperature: $2200^{\circ} \mathrm{C}$. 
TABLE IV

Results (mean \pm SD, $\mu \mathrm{g} \mathrm{g}^{-1}$ ) for Pb Determination $(\mathrm{n}=3)$ in $\mathrm{Rod}$ and Coating Fractions by the Proposed (HR-CS GFAAS) and Comparative (LS GFAAS) Methods

\begin{tabular}{cccccc}
\hline Rod Sample & SS HR-CS GFAAS & LS GFAAS & Coating Sample & SS HR-CS GFAAS & LS GFAAS \\
\hline R1 & $1.23 \pm 0.03$ & $1.88 \pm 0.09$ & C1 & $6.40 \pm 0.40$ & $6.54 \pm 0.06$ \\
R2 & $0.78 \pm 0.06$ & $0.72 \pm 0.02$ & $\mathrm{C} 2$ & $5.11 \pm 0.41$ & $5.24 \pm 0.04$ \\
R3 & $0.52 \pm 0.04$ & $<\mathrm{LQ}$ & $\mathrm{C} 3$ & $1.16 \pm 0.14$ & $1.12 \pm 0.01$ \\
R4 & $0.06 \pm 0.01$ & $<\mathrm{LQ}$ & $\mathrm{C} 4$ & $1.06 \pm 0.02$ & $0.98 \pm 0.01$ \\
R5 & $0.07 \pm 0.01$ & $<\mathrm{LQ}$ & $\mathrm{C} 5$ & $1.40 \pm 0.21$ & $1.19 \pm 0.18$ \\
R6 & $0.44 \pm 0.07$ & $<\mathrm{LQ}$ & $\mathrm{C} 6$ & $5.69 \pm 0.78$ & $5.07 \pm 0.30$ \\
R7 & $1.56 \pm 0.01$ & $1.73 \pm 0.01$ & $\mathrm{C} 7$ & $1.19 \pm 0.06$ & $1.12 \pm 0.10$ \\
R8 & $2.17 \pm 0.01$ & $2.61 \pm 0.01$ & $\mathrm{C} 8$ & $2.15 \pm 0.12$ & $1.12 \pm 0.27$ \\
R9 & $1.40 \pm 0.03$ & $1.79 \pm 0.09$ & $\mathrm{C} 9$ & $6.60 \pm 0.34$ & $6.89 \pm 0.29$ \\
\hline
\end{tabular}

ations may be related to the type of raw materials (chemical composition) employed in incense production.

\section{CONCLUSION}

The LS GFAAS method was an efficient comparative technique for lead determination in incense by HR-CS GFAAS using solid sampling. The proposed method determines $\mathrm{Pb}$ in solid samples directly without any conventional sample pretreatment. This procedure is environmentally friendly since the direct solid sample analysis significantly reduces the environmental impact caused by the use of hazardous reagents commonly employed for sample preparation with acid digestion. The results showed that lead present in incense may be released to the environment and open burning of incense may generate emissions of Pb-containing dust and fumes, which are toxic to humans by inhalation and dermal absorption. Further studies on this matter should be done.

\section{ACKNOWLEDGMENT}

The authors thank the São Paulo Research Foundation (FAPESP) for financially supporting this work (Grant \# 14/12595-1). The authors also thank the Conselho Nacional de Desenvolvimento Científico e
Tecnológico (CNPq) for fellowship to J.C. and M.A.B. and researchship to J.A.G.N. (Grant \#303255/2013-7).

$\overline{\text { Received March 14, } 2017 .}$

\section{REFERENCES}

1. S.C. Lee and B. Wang, Atmos. Environ. 38, 941 (2004).

2. L. Knight, A. Levin, and C. Mendenhall, Candles and incense as potential sources of indoor air pollution: market analysis and literature review. Lexington, KY, USA: National Risk Management, p. 53, (2001)

3. H. Chuang, T. Jones, Y. Chen, J. Bell, J. Wenger, and K. Bérubé, Anal. Bioanal. Chem. 401, 3095 (2011).

4. J.J. Jetter, Z. Guo, J.A. McBrian, and M.R. Flynn, Sci. Total Environ. 295, 51 (2002).

5. P. Kaewrueng, W. Siriwong, and S. Siripanich, J. Health Res. 27, 217 (2013).

6. D.J. Butcher and J. Sneddon, A practical guide to graphite furnace atomic absorption spectrometry. John Wiley, 1998.

7. D.L.G. Borges, A.F. da Silva, B. Welz, A.J. Curtius, and U. Heitmann, J. Anal. At. Spectrom. 21, 763 (2006).

8. N.S. Feichtmeier and K. Leopold, Anal. Bioanal. Chem. 406, 3887 (2014).
9. S. Atilgan, S. Akman, A. Baysal, Y. Bakircioglu, T. Szigeti, M. Óvári, and G. Záray, Spectrochim. Acta Part B, At. Spectrosc. 70, 33 (2012).

10. M. Krawczyk, M. Jeszka-Skowron, and $\mathrm{H}$. Matusiewicz, Microchem. J. 117, 138 (2014).

11. D.L.G. Borges, A.F. da Silva, A.J. Curtius, B. Welz, and U. Heitmann, Microchim. Acta. 154, 101 (2006).

12. A.F. da Silva, D.L.G. Borges, F.G. Lepri, B. Welz, A.J. Curtius, and U. Heitmann, Anal. Bioanal. Chem. 382, 1835 (2005).

13. L.J. Zhao, T. Ren, and R.G. Zhong, Anal. Lett. 45, 2467 (2012).

14. J.F. Rêgo, A. Virgilio, J.A. Nóbrega, and J.A. Gomes Neto, Talanta. 100, 21 (2012).

15. A. Virgilio, J.A. Nóbrega, J.F. Rêgo, and J.A. Gomes Neto, Spectrochim. Acta Part B, At. Spectrosc. 78, 58 (2012).

16. S. Gunduz and S. Akman, Food Chem. 141, 2634 (2013).

17. S. Kelestemur and M. Özcan, Microchem. J. 118, 55 (2015).

18. R. Lemaire, D. del Bianco, L. Garnier, and J.L. Beltramo, Anal. Lett. 46, 2265 (2013).

19. L.A. Currie, Anal. Chim. Acta. 391, 105 (1999)

20. U. Kurfüst, Solid sample analysis: direct and slurry sampling using GF-AAS and ETV-ICP. Springer, 1998. 